\title{
Tenencia de mascotas en pacientes inmunocomprometidos: actualización y consideraciones veterinarias y médicas
}

\author{
Javier López, Anamaría Peña, Regina Pérez y Katia Abarca
}

\footnotetext{
Hospital Veterinario Puente Alto, Santiago, Chile (JL). Pontificia Universidad Católica, Santiago, Chile.

Escuela de Medicina (RP, KA) Hospital Dr. Sótero del Río. Servicio de Pediatría (AP)

Los autores declaran no tener conflictos de interés. No hubo fuente de financiamiento.

Recibido: 10 de mayo 2012 Aceptado: 28 de noviembre 2012

Correspondencia a: Anamaría Peña Donati anapena@med.puc.cl
} 
grave. En pacientes adultos infectados con VIH, algunas infecciones zoonóticas se relacionan directamente con el recuento de linfocitos T CD4, como son criptococosis e infecciones por Mycobacterium avium complex (MAC) $\left(\mathrm{CD} 4<50\right.$ céls $\left./ \mathrm{mm}^{3}(\mathrm{AI})\right)$, diarrea por Microsporidium (CD4 < 200 céls $/ \mathrm{mm}^{3}$ ) ( AIII) y Cryptosporidium (CD4 $<200$ céls $/ / \mathrm{mm}^{3}$ ) $(\mathrm{BIII})^{8}$. En niños con infección por VIH, el riesgo de enfermedad diseminada por MAC es mayor si existe inmunosupresión grave de acuerdo al recuento de CD4 ( $>6$ años: $<50$ céls $/ \mathrm{mm}^{3}, 2-5$ años: $<75$ céls $/ \mathrm{mm}^{3}$, 1-2 años: $<500$ céls $/ \mathrm{mm}^{3},<1$ año: $<750$ céls $/ \mathrm{mm}^{3}$ ) (AII) ${ }^{9}$.

Aquellos pacientes con recuento CD4 $<200$ céls $/ \mathrm{mm}^{3}$ o receptores de trasplante hematopoyético deben evitar el contacto directo con diarrea o deposiciones de mascotas, particularmente animales vagabundos y perros o gatos bajo 6 meses de edad (BIII) $)^{8,10,11}$.

El grado de la evidencia que respalda las recomendaciones se indica en la tabla adjunta:

\begin{tabular}{|c|l|}
\hline $\begin{array}{c}\text { Grado de } \\
\text { evidencia }\end{array}$ & Tipo de diseño investigación \\
\hline I & $\begin{array}{l}\text { Evidencia obtenida de un meta-análisis o de al menos } \\
\text { un estudio randomizado, controlado }\end{array}$ \\
\hline II & $\begin{array}{l}\text { Evidencia obtenida de al menos un estudio controla- } \\
\text { do, no randomizado, con resultados de laboratorio }\end{array}$ \\
\hline III & $\begin{array}{l}\text { Evidencia obtenida de expertos, opinión y/o experien- } \\
\text { cia clínica de autoridades reconocidas }\end{array}$ \\
\hline
\end{tabular}

El grado de la recomendación que respalda las recomendaciones se indica en la tabla adjunta:

\begin{tabular}{|c|l|}
\hline $\begin{array}{c}\text { Grado de } \\
\text { recomendación }\end{array}$ & Fortaleza de las recomendaciones \\
\hline A & Evidencia fuerte a favor \\
\hline B & Evidencia moderada a favor \\
\hline C & Opcional \\
\hline D & No debe ofrecerse en forma rutinaria \\
\hline E & No debe usarse bajo condición alguna \\
\hline
\end{tabular}

\section{Información y antecedentes derivados de estudios nacionales}

\section{Tenencia de mascotas}

A pesar de que la mayoría de los médicos tratantes no recomienda la tenencia de mascotas en pacientes IC, ésta se reporta en un porcentaje no despreciable lo que implica un potencial riesgo de adquirir una zoonosis. Abarca reportó la presencia de mascotas en 58\% de los hogares de sujetos IC, tanto adultos como niños, siendo la gran mayoría perros y gatos ( 78 y $31 \%$, respectivamente), seguidos de aves $(21 \%)$ y mascotas exóticas (5\%). Este estudio, además documentó numerosas deficiencias en el cuidado de las mascotas, así como una alta frecuencia
Tabla 1. Principales infecciones transmitidas por perros

\begin{tabular}{|c|c|c|}
\hline Agente & Mecanismo de transmisión & Manifestaciones clínicas \\
\hline $\begin{array}{l}\text { Virus } \\
\text { Rabia }\end{array}$ & Mordedura & Rabia \\
\hline \multicolumn{3}{|l|}{ Bacterias } \\
\hline Brucella canis & $\begin{array}{l}\text { Contacto con secreciones geni- } \\
\text { tales, orina, restos placentarios }\end{array}$ & $\begin{array}{l}\text { Fiebre prolongada, compromi- } \\
\text { so cardíaco, óseo y meníngeo }\end{array}$ \\
\hline Leptospira sp & $\begin{array}{l}\text { Contacto con orina o agua } \\
\text { contaminada }\end{array}$ & $\begin{array}{l}\text { Fiebre, falla renal, hepática, } \\
\text { meningoencefalitis }\end{array}$ \\
\hline Pastereulla multocida & Mordeduras & $\begin{array}{l}\text { Celulitis, compromiso óseo y } \\
\text { tendíneo }\end{array}$ \\
\hline Campylobacter sp & Alimentos o agua contaminada & Diarrea \\
\hline Salmonella sp & Oro-fecal & Diarrea \\
\hline Bordetella bronchiseptica & $\begin{array}{l}\text { Contacto con secreciones } \\
\text { Contacto directo }\end{array}$ & Neumonía \\
\hline $\begin{array}{l}\text { Bartonella quintana, vinsonii } \\
\text { subespecies berkoffii, } \\
\text { elizabethae }\end{array}$ & $\begin{array}{l}\text { Mordedura, contacto con } \\
\text { saliva }\end{array}$ & $\begin{array}{l}\text { Angiomatosis bacilar, peliosis } \\
\text { hepática, bacteriemia, endo- } \\
\text { carditis }\end{array}$ \\
\hline \multicolumn{3}{|l|}{ Hongos } \\
\hline Malassezia pachydermatis & Contacto directo & Sepsis en IC \\
\hline Microsporum canis & Contacto directo & $\begin{array}{l}\text { Tiña, lesiones inflamatorias y } \\
\text { granulomatosas }\end{array}$ \\
\hline $\begin{array}{l}\text { Parásitos } \\
\text { Sarcoptes scabei var canis } \\
\text { Cheyletiella parasitovorax }\end{array}$ & Contacto directo & Sarna zoonótica \\
\hline Toxocara canis & $\begin{array}{l}\text { Ingestión de huevos larvados o } \\
\text { contacto con pelaje }\end{array}$ & $\begin{array}{l}\text { Eosinofilia, compromiso hepá- } \\
\text { tico, pulmonar, SNC y ocular }\end{array}$ \\
\hline Dipylidium caninum & Ingestión de pulga & $\begin{array}{l}\text { Irritabilidad, prurito, dolor } \\
\text { abdominal }\end{array}$ \\
\hline Giardia intestinalis & $\begin{array}{l}\text { Ingestión de quistes por ali- } \\
\text { mentos y agua contaminadas }\end{array}$ & Diarrea \\
\hline Cryptosporidium sp & $\begin{array}{l}\text { Ingestión de quistes por } \\
\text { alimentos, agua contaminada } \\
\text { por deposiciones }\end{array}$ & Diarrea \\
\hline
\end{tabular}

\section{Tabla 2. Principales infecciones transmitidas por gatos}

\begin{tabular}{|c|c|c|}
\hline Agente & Mecanismo de transmisión & Manifestaciones clínicas \\
\hline $\begin{array}{l}\text { Virus } \\
\text { Rabia }\end{array}$ & Mordedura & Rabia \\
\hline $\begin{array}{l}\text { Bacterias } \\
\text { Bartonella henselae }\end{array}$ & Mordedura o arañazo & $\begin{array}{l}\text { Enfermedad por arañazo de gato típica } \\
\text { o atípica, peliosis hepática, bacteriemia, } \\
\text { endocarditis }\end{array}$ \\
\hline $\begin{array}{l}\text { Pastereulla multocida } \\
\text { Campylobacter sp } \\
\text { Salmonella sp }\end{array}$ & $\begin{array}{l}\text { Mordedura } \\
\text { Oro-fecal } \\
\text { Oro-fecal }\end{array}$ & $\begin{array}{l}\text { Celulitis, compromiso óseo y tendíneo } \\
\text { Diarrea } \\
\text { Diarrea }\end{array}$ \\
\hline $\begin{array}{l}\text { Parásitos } \\
\text { Toxocara cati }\end{array}$ & Ingestión de huevos larvados & $\begin{array}{l}\text { Eosinofilia, compromiso hepático, pulmo- } \\
\text { nar, SNC y ocular }\end{array}$ \\
\hline Toxoplasma gondii & Ingestión de quistes & $\begin{array}{l}\text { Síndrome mononucleósico, compromiso } \\
\text { SNC y ocular }\end{array}$ \\
\hline $\begin{array}{l}\text { Hongos } \\
\text { Microsporum canis }\end{array}$ & Contacto directo & $\begin{array}{l}\text { Tiña, lesiones inflamatorias y granuloma- } \\
\text { tosas }\end{array}$ \\
\hline
\end{tabular}


Tabla 3. Agentes zoonóticos transmitidos por mascotas de importancia en pacientes inmunocomprometidos

\begin{tabular}{|c|c|c|c|}
\hline Agente & Animal & Mecanismos de transmisión & Manifestaciones clínicas \\
\hline \multicolumn{4}{|l|}{ Virus } \\
\hline $\begin{array}{l}\text { Virus de la coriomeningitis } \\
\text { linfocitaria }\end{array}$ & Ratones, hámsters & Saliva, orina, deposiciones, posiblemente mordeduras & $\begin{array}{l}\text { Meningoencefalitis, compromiso hepatorrenal; en } \\
\text { recién nacidos: compromiso de SNC y ocular }\end{array}$ \\
\hline Influenza A (H5N1) & Hurones, aves & Aerosoles de animales infectados & Influenza, neumonía \\
\hline Herpes B virus & Primates & Saliva, orina, mordeduras & Meningoencefalitis, mielitis \\
\hline \multicolumn{4}{|l|}{ Bacterias } \\
\hline Bordetella bronchiseptica & Perros y gatos & Aerosol & Neumonía \\
\hline $\begin{array}{l}\text { Bartonella henselae y otras } \\
\text { especies }\end{array}$ & Gatos, perros & Mordedura o rasguños & $\begin{array}{l}\text { Compromiso sistémico, angiomatosis bacilar, peliosis } \\
\text { hepática, esplenitis, endocarditis }\end{array}$ \\
\hline Brucella canis & Perros & Contacto con secreciones genitales, placenta y orina & Compromiso sistémico, óseo, endocárdico \\
\hline Campylobacter sp & Perros, gatos, pollos & Contacto deposiciones & Sepsis, endocarditis \\
\hline Chlamydophila felis & Gatos & Secreciones respiratorias & Conjuntivitis, neumonía \\
\hline Chlamydophila psittaci & Pájaros & Secreciones respiratorias y ocular & Neumonía \\
\hline Helicobacter cinaedi & Ratones, hámsters & Contacto con deposiciones & Sepsis y meningitis en recién nacidos \\
\hline Listeria monocytogenes & $\begin{array}{l}\text { Perros, gatos, cerdos, } \\
\text { vacunos }\end{array}$ & $\begin{array}{l}\text { Alimentos contaminados, contacto directo con } \\
\text { animales infectados }\end{array}$ & Meningitis, sepsis, meningitis o septicemia neonatal \\
\hline Mycobacterium avium complex & Pájaros & Secreciones respiratorias & Compromiso sistémico \\
\hline Mycobacterium marinum & Peces & Limpieza y manipulación & Lesiones cutáneas \\
\hline Pastereulla multocida & Gatos, perros & Mordedura & Sepsis, neumonía, peritonitis \\
\hline Rhodococcus equi & Caballos & Tierra contaminada con deposiciones de animales & Neumonía cavitaria \\
\hline Salmonella sp & $\begin{array}{l}\text { Tortugas, reptiles, iguanas, } \\
\text { gatos y perros }\end{array}$ & Contacto con deposiciones & Compromiso sistémico, meníngeo, óseo \\
\hline Streptobacillus moniliformis & Ratones & Mordedura & $\begin{array}{l}\text { Compromiso sistémico, endocárdico y articular, } \\
\text { exantema }\end{array}$ \\
\hline \multicolumn{4}{|l|}{ Hongos } \\
\hline Histoplasma capsulatum & Pájaros & Secreciones respiratorias & Neumonía \\
\hline Malassezia pachydermatis & Perros & Contacto directo & Sepsis, infección asociada a catéter \\
\hline $\begin{array}{l}\text { Microsporum canis } \\
\text { Trichophyton mentagrophytes }\end{array}$ & $\begin{array}{l}\text { Gatos, vacas, perros, } \\
\text { cabras, caballos, cerdos, } \\
\text { conejos, roedores }\end{array}$ & $\begin{array}{l}\text { Contacto directo o indirecto con animales asintomá- } \\
\text { ticos o con lesiones de piel de animales infectados, } \\
\text { pelos o caspa, fomites o ropa de cama contaminada }\end{array}$ & $\begin{array}{l}\text { Tinea capitis, descamación, enrojecimiento y } \\
\text { ocasionalmente vesículas o fisuras }\end{array}$ \\
\hline \multicolumn{4}{|l|}{ Parásitos } \\
\hline Cyclospora cayetanensis & Perros & Agua o alimentos contaminados con quistes & Diarrea crónica \\
\hline Cryptosporidium sp & Perros, gatos & Agua o alimentos contaminados con quistes & Diarrea crónica, colangiopatía \\
\hline Giardia intestinalis & Perros, gatos & Agua y alimentos contaminados con quistes & Diarrea crónica \\
\hline Microsporidium sp & Perros & Alimentos contaminados & Diarrea crónica, compromiso sistémico (VIH) \\
\hline $\begin{array}{l}\text { Toxocara canis } \\
\text { Toxocara cati }\end{array}$ & $\begin{array}{l}\text { Perros } \\
\text { Gatos }\end{array}$ & Ingestión de huevos, contacto directo pelaje & $\begin{array}{l}\text { Compromiso diseminado en animales de experimenta- } \\
\text { ción inmunosuprimidos }\end{array}$ \\
\hline Toxoplasma gondii & Gatos & Contacto con deposiciones o ingestión de carne cruda & Compromiso SNC, corioretinitis, infección neonatal \\
\hline $\begin{array}{l}\text { Sarcoptes scabiei, Cheyletidae, } \\
\text { Dermanysside, Macronyssidae, } \\
\text { Trixacarus caviae }\end{array}$ & Conejos, roedores & Contacto directo & $\begin{array}{l}\text { Dermatitis, infección transitoria si ácaros no se repro- } \\
\text { ducen en la piel, sarna noruega }\end{array}$ \\
\hline
\end{tabular}

de mordeduras por perros ${ }^{12}$. En otro estudio nacional, $67 \%$ de las familias de niños IC (con infección por VIH, oncológicos o sometidos a trasplantes) declaró tener mascotas: $86 \%$ perros, $21 \%$ gatos y $17 \%$ otras mascotas (aves, roedores, conejos y tortugas de tierra). Se detectaron conductas de riesgo en los niños y muy baja adherencia al control veterinario, con un alto incumplimiento de inmunizaciones y desparasitaciones ${ }^{13}$.

\section{Zoonosis relacionadas a mascotas en pacientes inmunocomprometidos}

Los pacientes IC tienen mayor riesgo de adquirir una zoonosis, lo que está documentado en la literatura médica $^{3}$, principalmente en pacientes infectados con $\mathrm{VIH}$, en quienes las zoonosis corresponden a varias de las enfermedades indicadoras de SIDA cuya prevalencia se ha estudiado. En estos pacientes, las mascotas también son 
potenciales fuentes de una serie de agentes oportunistas principalmente intestinales, tales como Salmonella spp, Campylobacter spp, Microsporidium $\mathrm{sp}^{14}$ y otros enteroparásitos, cuya prevalencia se desconoce. Escasos reportes nacionales describen la frecuencia de agentes zoonóticos en este grupo de pacientes. Tassara y cols. reportaron en niños infectados con VIH, el hallazgo de Giardia intestinalis en tres casos de diarrea aguda, Cryptosporidium parvum en seis, cinco de ellos con diarrea crónica y Microsporidium $\mathrm{sp}$ en dos niños con diarrea crónica ${ }^{15}$. En la cohorte nacional de SIDA Pediátrico se reportaron seis casos de criptosporidiosis en 235 niños, cinco de ellos fallecieron por el evento ${ }^{16}$. En otro estudio nacional se describió un caso de infección por $G$. intestinalis en un niño con SIDA y en su mascota ${ }^{13}$. Neira describió especies zoonóticas de Cryptosporidium en cerca de $20 \%$ de un grupo de pacientes adultos IC (infectados por VIH, oncológicos o sometidos a trasplantes) ${ }^{17}$.

\section{Detección de agentes zoonóticos en mascotas}

Un estudio clínico de las mascotas de niños chilenos IC reveló una alta frecuencia de enfermedades y presencia de vectores, varios de ellos de importancia zoonótica: 59\% de los perros evaluados presentaban ectoparásitos (garrapatas y pulgas), $24 \%$ dermatofitos y $42 \%$ enteroparásitos; cuatro perros tenían una infección zoonótica (brucelosis, sospecha de leptospirosis, escabiosis y dipilidiasis). De los gatos evaluados, $71 \%$ tenía pulgas y $43 \%$ dermatofitos y enteroparásitos ${ }^{13}$.

\section{Parásitos intestinales}

En el ámbito veterinario, estudios locales reportan una elevada prevalencia de parásitos intestinales con potencial zoonótico en perros y gatos con diarrea: $G$. intestinalis $22 \%$, Toxocara canis $11 \%$ y Toxocara cati $10 \%$, y en menor porcentaje: Dipylidium caninum 7\%, Toxoplasma gondii 4\% y Ancylostomideos 2\%. Los canes bajo 6 meses de edad tuvieron una significativa mayor infección por protozoos intestinales $(G$. intestinalis, Blastocystis sp, Ameba sp e Isospora sp) y helmintos ( $T$. canis $)^{18}$. En caninos asintomáticos de familias de la zona sur de Santiago se encontró Cryptosporidium sp en $4 \%$ ${ }^{19}$, y en otro estudio no publicado, se encontró este agente en la misma proporción en gatos sintomáticos y en dos de cuatro hurones estudiados, así como una alta tasa de infección por $G$. intestinalis, $T$. canis y Cryptosporidium sp en perros de ocho tiendas de mascotas de la Región Metropolitana $^{20}$.

\section{Ectoparásitos}

Los parásitos externos de las mascotas constituyen un problema sanitario, ya sea por acción directa o por su rol como vectores de agentes zoonóticos, algunos de ellos de reciente reconocimiento. Dentro de los ectoparásitos, la pulga del gato, especie encontrada frecuentemente en los perros de nuestro país ${ }^{21}$ tiene un conocido rol en la epidemiología de la enfermedad por arañazo de gato causada por $B$. henselae, agente detectado en nuestro país desde hace más de una década. La pulga del gato también es vector y reservorio de Rickettsia felis, agente emergente causante de una rickettsiosis del grupo de las denominadas fiebres manchadas ${ }^{22}$. Esta rickettsia ha sido identificada en pulgas de gatos de una vivienda de la comuna de Puente Alto en la Región Metropolitana, donde se encontró su presencia en $70 \%$ de las pulgas mediante la técnica de RPC y en un alto porcentaje de estos gatos se detectó serología positiva a $R$. feli $s^{23}$. También se ha documentado la presencia de este agente en garrapatas de perros provenientes del mismo sector ${ }^{24}$.

Otros ectoparásitos de importancia epidemiológica son las garrapatas, cuya especie predominante entre las regiones de Arica-Parinacota ( $\mathrm{I}^{\circ}$ Región) y Araucanía (IX ${ }^{\circ}$ Región) de Chile, es Riphicephalus sanguineus, conocida como garrapata café del perro ${ }^{25}$, potencial transmisora de múltiples agentes infecciosos, entre ellos Ehrlichia canis y algunas rickettsias. Recientemente se ha descrito en nuestro país la presencia de E. canis en la Región de Arica-Parinacota ${ }^{26}$, la que causa ehrlichiosis monocítica en humanos ${ }^{27}$.

La sarna, producida por Sarcoptes scabiei var canis y Cheyletiella parasitovorax, es otra ectoparasitosis importante desde el punto de vista zoonótico y es la zoonosis más prevalente en nuestro país, de acuerdo a reportes de un sistema de vigilancia de mascotas efectuado en la $\mathrm{R}$. Metropolitana ${ }^{28}$.

\section{Bacterias}

Dentro de las infecciones zoonóticas de origen bacteriano, diversas especies del género Bartonella (henselae, quintana, vinsonii subespecie berkhoffi, elizabethae y clarridgeiae) tienen especial relevancia y están asociadas, como se mencionó anteriormente, a vectores tales como pulgas y garrapatas que parasitan gatos y perros ${ }^{29-32}$. En nuestro país se han descrito dos especies: $B$. henselae ${ }^{33,34}$ y B. quintana $a^{35,36}$, siendo la primera de mayor importancia médica. La presentación clínica de la infección por $B$. henselae incluye la forma clásica con adenopatía cercana al sitio de inoculación, así como las formas atípicas con compromiso hepato-esplénico, óseo, endocárdico, encefálico, ocular y fiebre prolongada ${ }^{37-42}$. Los reportes locales son mayoritariamente de pacientes inmunocompetentes y su prevalencia en IC es desconocida. En cuanto a $B$. quintana, el primer caso de angiomatosis bacilar por este agente en Chile fue descrito en un paciente con SIDA ${ }^{36}$; sin embargo, no se comprobó el origen vectorial de la infección. En otros países se ha encontrado una alta seroprevalencia de Bartonella sp en adultos con infección por VIH $(38,4 \% \text { en Brasil, } 22,3 \% \text { en España })^{43,44}$ y una 
estrecha asociación entre contacto con gatos y desarrollo de infección; recientemente se ha relacionado también al perro como fuente de infección ${ }^{30-32}$.

Otra bacteria de importancia asociada a las mascotas es Brucella canis, agente causante de brucelosis en humanos y perros, cuya seroprevalencia es de $12 \%$ en perros consultantes en clínicas veterinarias de la R. Metropolitana ${ }^{45}$, cifra que aumenta en criaderos ${ }^{46}$. En un estudio nacional, Abarca describió un caso de infección asintomática por $B$. canis en una niña de 15 meses portadora de neutropenia crónica y en su mascota canina ${ }^{13}$.

Recientemente se ha descrito como fuente de infección cruzada el consumo de productos alimentarios para mascotas de origen comercial, conducta presente en algunos niños ${ }^{13}$. En los últimos años ha habido un incremento de reportes de presencia de bacterias enteropatógenas en estos productos, tales como Salmonella montevideo ${ }^{47-50}$, causante de brotes de diarrea tanto en animales como humanos. En un estudio nacional sobre gastroenteritis hemorrágica en caninos se aisló este agente en el alimento comercial $^{50}$.

\section{Hongos}

Las infecciones micóticas más frecuentes en las mascotas son producidas por Malassezia pachydermatis, hongo causante de otitis y dermatitis en perros, y las dermatofitosis por Microsporum canis detectadas en gatos sanos. Estas dermatomicosis constituyen fuentes de infección para humanos en quienes producen enfermedad inflamatoria cutánea que puede dar origen a infecciones bacterianas secundarias graves incluyendo sepsis en $\mathrm{IC}^{51-53}$. Estudios chilenos revelan alta frecuencia de portación de Malassezia sp (34,1\%) en los oídos de perros de raza cocker spaniel de la $\mathrm{R}$. Metropolitana ${ }^{54}$. También es importante considerar la presencia de Candida albicans en los oídos de perros con otitis externa ${ }^{5}$, agente causante de infecciones graves en IC.

\section{Recomendaciones según tipo de mascota}

A continuación se detallan recomendaciones derivadas de la revisión bibliográfica internacional y nacional, con el propósito de contribuir en la reducción del riesgo de transmisión de los agentes zoonóticos más frecuentemente encontrados en las mascotas predominantes en las familias chilenas (perros y gatos). Estas recomendaciones están referidas a los siguientes aspectos: elección de la mascota, principales agentes con potencial zoonótico, inmunizaciones y alimentación.

\section{Elección de la mascota canina}

Existen varios factores que las familias de pacientes IC deberían considerar para adoptar una mascota canina, dentro de los cuales destacan el origen del animal, su raza y edad.

Se recomienda evitar recoger animales abandonados y tener precaución al adquirir cachorros bajo 6 meses de edad, debido a que éstos presentan mayores tasas de infestación por parásitos intestinales ${ }^{18}$. Se deben extremar las precauciones al adquirir mascotas desde tiendas comerciales por la alta prevalencia de infecciones parasitarias como giardiasis ${ }^{20}$ y ectoparasitarias como sarna, recomendándose que sean sometidas a un control veterinario clínico y de laboratorio previo al ingreso de la mascota al hogar.

Con respecto a la raza, es necesario tomar en cuenta ciertas características del animal que lo hagan más adecuado para la relación con niños y adultos, tales como su tamaño, obediencia y docilidad. Las razas de mayor agresividad, y por lo tanto con más riesgo de mordeduras, de acuerdo a varios estudios, son las siguientes, incluidas sus cruzas: Pastor alemán, Rottweiler, Pit bull, ChowChow y Akitas ${ }^{55-61}$. Sin embargo, se debe tener presente que en cada raza hay individuos de mayor docilidad y otros más agresivos y dominantes, por lo que es muy importante la evaluación conductual de cada animal. Además, se deben evitar ciertas conductas de las personas que pueden desencadenar agresividad en el perro ${ }^{58}$, tales como invadir su comida cuando está alimentándose, establecer contacto físico con animales desconocidos o conocidos pero con antecedentes previos de mordeduras y la presencia de niños pequeños en compañía del animal sin la supervisión de un adulto ${ }^{55,59}$.

\section{Elección de la mascota felina}

Evitar el recoger gatos de corta edad abandonados, por el riesgo de transmisión de agentes infecciosos prevalentes en ellos debido a las malas condiciones sanitarias, alta frecuencia de inmunosupresión secundaria al virus de leucemia (VLFe) e inmunodeficiencia felina (VIF) y conducta agresiva. En caso de adquirir un gato en tienda de mascota o criadero, debe ser sometido a examen clínico y de laboratorio según se detalla en el punto siguiente.

\section{Consideraciones sobre los principales agentes con potencial zoonótico en perros}

El control veterinario periódico es fundamental para la pesquisa y prevención de agentes con potencial zoonótico, siendo los más importantes las bacterias de la cavidad oral, B. canis, Bordetella bronchiseptica, Staphylococcus, levaduras, bacterias y parásitos intestinales y ectoparásitos.

Bacterias de la cavidad oral: En la cavidad oral del perro habitan bacterias aeróbicas (Pasteurella multocida y otras especies como $P$. septica, $P$. canis y $P$. dagmatis, Staphylococcus aureus, Streptococcus sp, Moraxella sp, 
Neisseria sp, Corynebacterium sp, Eikenella corrodens, Capnocytophaga canimorsus, Bergeyella zoohelcum, Bartonella), y anaeróbicas estrictas (Bacteroides fragilis, Fusobacterium sp y Veillonella parvula), las que se pueden transmitir a través de mordeduras o lamidos ${ }^{62}$. Por lo tanto, se debe evitar la exposición a la saliva del animal a través de lamidos, besos en su hocico y contacto de la saliva con heridas. En caso de contacto con saliva se recomienda el lavado prolijo de la zona expuesta con agua y jabón o uso de alcohol gel; para actividades que impliquen contacto con saliva o con el hocico del animal es imprescindible el uso de guantes.

Es primordial el control sanitario bucal de la mascota mediante examen clínico veterinario y cepillado dental efectuado por personas inmunocompetentes, con una periodicidad variable de acuerdo a la raza y tipo de alimentación de la mascota. Estas medidas deben extremarse en perros de razas pequeñas tales como Poodle, Fox terrier, Yorkshire, por su predisposición genética a las enfermedades periodontales ${ }^{63}$. Se recomienda la aplicación local de antisépticos (clorhexidina) en animales adultos (sobre 3 años) y seniles, así como destartraje en caso de enfermedad periodontal y tratamiento antimicrobiano. Otra medida que ayuda a evitar la infección periodontal es la adecuada alimentación en base a fibra, huesos y alimento comercial.

Brucella canis: Este agente debe sospecharse en perros con sintomatología reproductiva como infertilidad, aborto, infección uterina, orquitis o epididimitis. Los animales infectados excretan la bacteria por la orina, secreciones genitales y restos placentarios, cuyo contacto constituye un factor de riesgo para humanos. Es recomendable efectuar estudio serológico a aquellos perros con sospecha clínica o epidemiológica, especialmente a los adquiridos en tiendas de mascotas o criaderos, así como los recogidos de la calle y evitar todo contacto de personas IC con la orina, secreciones genitales y restos placentarios. También evitar contacto con animales que tengan clínica sugerente o serología positiva para $B$. canis.

Bordetella bronchiseptica: Este agente ha sido recientemente identificado en infecciones respiratorias moderadas y neumonías de pacientes IC con antecedente de contacto con perros sintomáticos con cuadros de traqueobronquitis ${ }^{64-66}$. Los perros con alta sospecha clínica deben ser estudiados con cultivo de secreción traqueal tomados por vía endoscópica y tratados con antimicrobianos de amplio espectro.

Staphylococcus: En infecciones de piel y conducto auditivo externo de perros se detectan con frecuencia Staphylococcus intermedius y $S$. aureus ${ }^{67}$. Un potencial agente de transmisión entre humanos y animales es $S$. au- reus resistente a cloxacilina (meticilina) (SARM), que ha sido encontrado tanto en veterinarios asintomáticos como en animales portadores y sintomáticos, constituyéndose los perros en un posible reservorio de SARM adquirido en la comunidad ${ }^{68-71}$. Frente a la sospecha clínica de este agente, es necesario efectuar estudio microbiológico. Una medida de prevención consiste en aplicar baños con jabón antiséptico en perros de razas especialmente susceptibles de cursar con piodermas recurrentes como son aquellos de pelo largo ${ }^{5}$. Un factor de riesgo de dermatitis y sobreinfección bacteriana es el empleo de champú de uso humano, por lo que se recomienda utilizar exclusivamente productos de uso veterinario adecuados.

Levaduras: Su búsqueda debe efectuarse en los oídos y la piel en general. En los perros, Malassezia sp es un habitante común del oído sano y Candida sp del oído enfermo. Es necesario efectuar cultivo rutinario de la piel del conducto auditivo externo para determinar el estado de portación y eventualmente usar antimicóticos locales como medida preventiva. Las lesiones clínicas que sugieran micosis deben ser estudiadas con cultivo y tratadas oportunamente. La persona IC debe evitar el contacto con lesiones de piel sugerentes de micosis y con secreciones óticas de perros o en quienes se haya aislado alguno de estos agentes.

Bacterias y parásitos intestinales: Es recomendable efectuar una búsqueda activa de agentes infecciosos digestivos mediante la realización de algunos test diagnósticos como coprocultivo para Salmonella, Escherichia coli y Campylobacter en caso de cuadros diarreicos, y parasitológico seriado rutinario una vez al año con tinción Burrows y Ziehl-Neelsen modificado para pesquisa de Giardia y Cryptosporidum sp, respectivamente ${ }^{18}$ en mascotas de pacientes IC. Se recomienda el tratamiento preventivo con antihelmínticos de amplio espectro cada tres meses a partir de los 15 días de vida y antiprotozoarios, al menos en una ocasión, en cachorros y adultos.

En las razas de pelo largo es necesario mantener el aseo de la zona perianal ya que se ha detectado la presencia de huevos de $T$. canis larvados adheridos al pelaje de esta zona $^{72}$. Se debe educar a los pacientes IC a evitar todo contacto con deposiciones y con la zona perianal de los perros.

Ectoparásitos: El control de ectoparásitos, pulgas y garrapatas debe realizarse en forma preventiva durante las estaciones de primavera y verano mediante el uso de collares, aerosol o pipetas con garrapaticidas de acción prolongada, de acuerdo a la recomendación del fabricante. Cuando se detectan garrapatas en el cuerpo del animal se deben extraer utilizando guantes y pinzas adecuadas, así como aplicar garrapaticidas en el perímetro exterior 
de la propiedad. Desde el punto de vista de transmisión de agentes, existen diferencias de acuerdo al mecanismo de acción del garrapaticida, siendo más efectivos los productos que actúan por contacto y causan la muerte del parásito antes de que muerda al animal, evitando así la transmisión de patógenos, comparados con los de acción sistémica que provocan su muerte tardía no evitando esta transmisión ${ }^{73}$.

El control de las pulgas, debe efectuarse mediante el uso de pulguicidas en pipetas. Este tratamiento debe incluir a todas las mascotas que conviven con el perro.

Otro ectoparásito es S. scabiei var canis que infesta más frecuentemente a los cachorros y perros senescentes produciendo dermatitis alérgica con alopecia, y en el humano una dermatitis muy pruriginosa. El diagnóstico es clínico y su prevención se basa en el confinamiento y evitar el contacto con perros de la calle. Existen collares que contienen amitraz, antiparasitario externo con efecto antisárnico y garrapaticida que serían recomendables en mascotas de pacientes IC.

\section{Consideraciones sobre los principales agentes con potencial zoonótico en gatos}

Los microorganismos con potencial zoonótico más importantes son las bacterias de la cavidad oral, $B$. henselae, dermatofitos, T. gondii, parásitos intestinales y ectoparásitos. Con menor frecuencia se han descrito $R$. felis y Mycobacterium leprae.

Bacterias de la cavidad oral: En la cavidad oral del gato predominan bacterias gramnegativas como $P$. multocida ${ }^{72,74}$ y C. canimorsus, además de otras aerobias y anaerobias estrictas. La mordedura de gato suele ser profunda y puede alcanzar al hueso; se desprende la recomendación de evitar juegos agresivos con el animal, así como consultar precozmente en caso de mordedura para determinar la profundidad de la lesión. Es recomendable mantener el aseo bucal mediante limpieza y destartraje anual efectuado por un veterinario ya que en esta especie se requiere anestesia y/o sedación. Esta medida es particularmente importante en gatos con enfermedad inmunosupresora como la leucemia e inmunodeficiencia felina.

Bartonella henselae: Este agente que causa la enfermedad por arañazo de gato, entidad clínica de alta prevalencia en pacientes inmunocompetentes, puede producir una enfermedad diseminada grave en $\mathrm{IC}^{7,9,75}$; de ahí la importancia de su prevención y control en gatos. La mayor prevalencia se encuentra en gatos bajo 1 año de edad, de hábito callejero ${ }^{33}$, e infestados con pulgas (Ctenocephalides felis $)^{75-77}$. Esta última condición perpetúa la infección en el gato y es fuente de transmisión al perro, por lo tanto es perentorio mantener un adecuado control de las pulgas en los gatos, mediante pulguicidas sistémicos. Las vías de transmisión más importantes de la enfermedad por arañazo de gato, son a través de la saliva y el arañazo del animal portador, y las medidas de prevención se basan en evitar los juegos rudos para impedir agresiones, uso de protectores de uñas para gatos y lavado profuso con agua y jabón de las heridas provocadas por la mascota.

Un reciente estudio demuestra una significativa asociación entre la mayor susceptibilidad a la infección por $B$. henselae en el animal, ya sea latente o progresiva, y la infección por el $\mathrm{VLFe}^{78}$. Si bien este virus no se ha aislado en nuestro país, existe evidencia clínica ${ }^{28}$ y serológica $^{79}$ de su presencia, por lo tanto su prevención a través de la inmunización periódica es especialmente relevante, considerando que causa una enfermedad de frecuente presentación en Chile ${ }^{28}$. Es recomendable que los pacientes IC adquieran gatos libres del VLFe para lo cual es necesario realizar un estudio serológico, el que está disponible en el país. En el caso de que el gato sea portador del VLFe sería importante descartar la infección por $B$. henselae mediante hemocultivo y/o RPC en sangre o tejidos, técnicas aún no disponibles ampliamente en el país. Una medida alternativa sería efectuar terapia empírica cuya efectividad no ha sido comprobada, pero que podría disminuir la carga de bacteriemia y por ende el riesgo para el paciente $\mathrm{IC}^{78}$.

Dermatofitos: La dermatomicosis o tiña, producida por $M$. canis, constituye una de las principales enfermedades zoonóticas transmitidas por gatos ${ }^{28}$, siendo el principal factor de riesgo el contacto con gatos bajo 6 meses de edad, con malas condiciones nutricionales y sanitarias, IC o abandonados, y su principal medida de prevención es evitar el contacto con ellos ${ }^{5}$. A pesar de que en un alto porcentaje de gatos el estudio micológico de su piel demuestra la presencia del hongo, la mayoría es asintomático. Sin embargo, es fuente de contaminación del ambiente y fomites, pudiendo infectar al hombre ${ }^{51,52}$, y en pacientes IC, puede producir lesiones inflamatorias y granulomatosas. El tratamiento en la mascota incluye antimicóticos sistémicos y tópicos.

Toxoplasma gondii: Aunque toxoplasmosis es una potencial zoonosis transmitida por gatos, estudios en mujeres embarazadas con infección aguda demostraron que el principal factor de riesgo de adquirirla es el consumo de carne de cerdo, cordero o cabra insuficientemente cocidas o crudas, mientras que no se encontró una asociación estadísticamente significativa entre el contacto con gatos, ya fuese cachorros o adultos, y sus heces e infección ${ }^{80}$. Sólo $\%$ de los gatos excreta ooquistes en las deposiciones durante la infección aguda y por un período de dos semanas, no representando mayor relevancia en la patogenia de la infección humana ${ }^{5,81}$. La forma de presentación más frecuente de la infección aguda en el 
gato es diarrea auto-limitada sin compromiso sistémico, por lo que el diagnóstico debe efectuarse a través de un examen copro-parasitológico. La prevención de la toxoplasmosis felina se basa en su alimentación con alimentos comerciales, evitando la ingesta de carne cruda y de posibles hospederos intermediarios como los roedores. Considerando la vía de transmisión, es recomendable que los pacientes IC eviten el contacto con deposiciones de gatos. Los ooquistes requieren al menos $24 \mathrm{hrs}$ a temperatura ambiente para esporular y ser infectantes; la eliminación diaria de las deposiciones contenidas en cajas de arena minimiza la posibilidad de infección con ooquistes infectantes.

Parásitos intestinales: Dentro de las enfermedades parasitarias producidas por helmintos, la más importante es la infestación por T. cati, causante del síndrome de larva migrans en el humano. Su control se basa en la desparasitación periódica, al menos cada tres meses, con antihelmínticos que además controlan la tenia Dipylidium caninum, la que puede transmitirse al hombre por la ingestión accidental de pulgas infestadas. Dentro de los protozoos, los más relevantes son G. intestinalis y Crytosporidium $\mathrm{sp}^{18}$. Es recomendable la desparasitación preventiva en todas las edades con anti-protozoarios anualmente o según resultado del estudio copro-parasitológico.

Ectoparásitos: El ectoparásito más frecuente del gato es la pulga, principalmente la especie $C$. felis, pero esta mascota también puede infestarse con Ctenocefalides canis y Pulex irritans y también puede ser un hospedero accidental de la garrapata café del perro. Su control se basa en el examen periódico y el uso pulguicidas y garrapaticidas de acción tópica. La pulga del gato también es vector reconocido de $R$. felis, desconociéndose a la fecha las manifestaciones clínicas de la infección en el felino. Las medidas de prevención incluyen el confinamiento del animal y el control de pulgas en todas las mascotas del hogar.

Mycobacterium leprae: Se ha documentado como un importante agente causal de abscesos y flegmones recurrentes en gatos ${ }^{82}$, entidades clínicas diagnosticadas con frecuencia en la práctica clínica veterinaria, especialmente en gatos infectados con el VLFe y VIF. Este tipo de lesiones deben ser tratadas adecuadamente tomando las medidas de precaución necesarias para evitar el riesgo de transmisión al paciente IC. El diagnóstico se efectúa con tinción de Ziehl Neelsen y el tratamiento es con antimicrobianos específicos.

\section{Inmunizaciones para perros}

Los perros deben vacunarse a partir de las 6 semanas de edad con tres dosis de vacuna séxtuple u óctuple durante el primer año y anualmente de por vida. Estas vacunas brindan protección contra el virus distemper, adenovirus serotipo 1 y 2, parvovirus, Leptospira canicola y L. hemorrágica; se agrega coronavirus y parainfluenza en la óctuple. De estos agentes, los únicos estudiados y aislados en Chile son Leptospira, parvovirus ${ }^{50,83}$ y virus distemper ${ }^{28,84}$. Este último causa inmunosupresión en el animal, con la posibilidad de adquirir infecciones bacterianas y micóticas con potencial zoonótico que pueden ser de riesgo para pacientes IC.

Recientemente se comercializa en nuestro país una vacuna viva atenuada de aplicación intranasal contra $B$. bronchiseptica para perros, de uso anual, que sería de utilidad si se administra previo al ingreso de la mascota al hogar de un paciente IC o si el animal es confinado durante 6 semanas debido a que puede excretar la bacteria durante ese período pudiendo infectar al paciente ${ }^{85}$.

Si bien el virus de la rabia variante canina no circula en nuestro país hace más de tres décadas, el perro mantiene su potencial rol transmisor por eventuales contactos con murciélagos, especie reservorio de este virus en Chile ${ }^{86}$. Las vacunas disponibles actualmente son elaboradas en cultivos celulares, tienen menos reacciones adversas y producen inmunidad más duradera que la histórica vacuna Fuenzalida Palacios (preparada en cerebro de ratón lactante $)^{87}$, por lo que se recomienda su administración cada dos años.

\section{Inmunizaciones para gatos}

Las inmunizaciones recomendadas para los gatos y disponibles en nuestro país son la vacuna triple felina que protege contra los virus herpes, calicivirus y panleucopenia y se administra en gatos antes de 1 año de edad, y las vacunas contra el VLFe y antirábica, recomendadas a partir de los 5-6 meses de edad, con intervalos de acuerdo a la recomendación del fabricante.

\section{Alimentación para perros y gatos}

Considerando la posibilidad de contaminación de los alimentos con bacterias enteropatógenas, es recomendable el consumo de alimentos de uso comercial envasados, certificados, almacenados y administrados a la mascota en forma adecuada, o una dieta casera. En los gatos debe evitarse la ingestión de carne cruda.

En la Tabla 4 se resumen las principales recomendaciones para evitar zoonosis transmitidas por perros y gatos.

\section{Otras mascotas}

Los pacientes IC deben evitar el contacto con aves, peces, conejos, reptiles, roedores incluyendo hamsters, primates no humanos (monos), hurones, así como animales salvajes, debido a la posibilidad de adquirir infecciones zoonóticas graves ${ }^{4,5,10}$ (Tabla 3 ). 


\begin{tabular}{|c|c|c|}
\hline Recomendaciones & Perro & Gato \\
\hline Elección de la mascota & $\begin{array}{l}\text { Raza no agresiva } \\
\text { Precaución con mascotas abandonadas, de criadero o mascotería }\end{array}$ & $\begin{array}{l}\text { Precaución con mascotas abandonadas, de criadero o tienda de } \\
\text { mascotas }\end{array}$ \\
\hline Prevención de infecciones & \multicolumn{2}{|c|}{$\begin{array}{l}\text { Control sanitario bucal } \\
\text { Control veterinario clínico } \\
\text { Desparasitación interna y externa } \\
\text { Inmunizaciones }\end{array}$} \\
\hline Detección de agentes zoonóticos & $\begin{array}{l}\text { Examen clínico veterinario } \\
\text { Coproparasitológico con tinción Burrows y Ziehl-Neelsen anual y } \\
\text { en episodios de diarrea } \\
\text { Coprocultivo en episodios de diarrea } \\
\text { Estudio serológico de acuerdo a sospecha clínica y epidemiológica } \\
\text { Cultivo micológico del conducto auditivo externo como tamizaje } \\
\text { Cultivo bacteriológico de piel de acuerdo a la expresión clínica }\end{array}$ & $\begin{array}{l}\text { Examen clínico veterinario } \\
\text { Coproparasitológico con tinción Burrows y Ziehl-Neelsen anual y } \\
\text { en episodios de diarrea } \\
\text { Serología para virus de leucemia e inmunodeficiencia felina } \\
\text { Cultivo micológico de acuerdo a clínica } \\
\text { Cultivo bacteriológico y tinción Ziehl Neelsen en flegmón }\end{array}$ \\
\hline \multirow[t]{2}{*}{ Alimentación } & \multicolumn{2}{|c|}{ Alimentos comerciales envasados o comida casera } \\
\hline & & Evitar la ingesta de carne cruda \\
\hline Ambiente & Saneamiento ambiental (control & de vectores y manejo de basura) \\
\hline
\end{tabular}

\section{Conclusiones}

La tenencia de mascotas brinda beneficios indiscutidos en los pacientes IC. Sin embargo, constituye un potencial riesgo de adquisición de múltiples agentes infecciosos potencialmente graves e incluso fatales en esta vulnerable población. Por ello, es necesario que el equipo de salud entregue orientaciones sobre sus cuidados a fin de minimizar este riesgo. Estudios nacionales en mascotas han revelado la presencia de múltiples patógenos cuyo real impacto en el paciente IC no ha sido precisado, y considerando que no se efectúa estudio etiológico rutinario en los animales es posible suponer que existan muchos otros agentes con potencial zoonótico aún no identificados.

Si bien en este documento se entregan pautas generales para evitar la transmisión de agentes zoonóticos al paciente IC a partir de las mascotas, es importante considerar la realización de un estudio de laboratorio básico en cada binomio paciente-mascota con la finalidad de efectuar recomendaciones más específicas.

\section{Resumen}

La tenencia de mascotas ofrece beneficios indiscutidos a los pacientes inmunocomprometidos (IC); sin embargo, representa un riesgo de adquirir una zoonosis potencialmente grave. Se describen los mecanismos de transmisión y la forma de presentación de las principales infecciones zoonóticas de perros y gatos que pueden afectar a los pacientes IC, así como la información internacional actualizada y antecedentes derivados de estudios nacionales. A partir de ello, se indican las recomendaciones más relevantes para estos pacientes y sus familias, tanto para la selección de la mascota, como para su cuidado posterior, que garantice una tenencia responsable y segura que permita prevenir, pesquisar y tratar las infecciones oportunamente.

\section{Referencias bibliográficas}

1.- Owen C, Nightingale C, Rudnicka A, Ekelund U, McMinn A, Van Sluijs E et al. Family dog ownership and levels of physical activity in childhood: findings from the child heart and health study in England. Am J Public Health 2010; 100: 1669-71.

2.- Torres M, López J, Solari V, Jofré L, Abarca K, Perret C. Recomendaciones para el cuidado y manejo responsable de mascotas y su impacto en salud humana. Comité de Infecciones Emergentes, Sociedad Chilena de Infectología, 2005. www.sochinf.cl

3.- Hemsworth S, Pizer B. Pet ownership in immunocompromised children-A review of the literature and survey of existing guidelines. Eur J Oncol Nursing; 2006; 10: 117-27.

4.- Mani I, Maguire J. Small animal zoonoses and immuncompromised pet owners. Top companion Anim Med. 2009; 24 (4): 164-74.

5.- Greene C. Enfermedades infecciosas del perro y del gato. Capítulo 99: Personas inmunocomprometidas e infecciones compartidas por seres humanos y animales: zoonosis, sapronosis y antroponosis. Greene $\mathrm{C}$ and Levy Julie $3^{\mathrm{a}}$ Edición, México, editorial Mc Graw Hill Interamericana, año 2007, Volumen 2, pág 1153-73.

6.- Glaser C, Lewis P, Wong S. Pet, animal and vector borne infections. Pediatr Rev 2000; 21 (7): 219-32.

7.- Kaufmann F, Engelhart S, Glasmacher A, Exner M. Risk of infection and preventive strategies in the domestic environment of immunosuppressed hematologic oncology patients. Med Klin (Munich) 2002; 97 (1): 22-9.

8.- Guidelines for prevention and treatment of opportunistic infections in HIV- infected adults and adolescents. MMWR Morb Mortal Wkly Rep 2009 (April 10); 58, No. RR-4.

9.- Guidelines for the prevention and treatment of opportunistic infections among HIV- exposed and HIV- infected children. MMWR Morb Mortal Wkly Rep 2009; 58, No.RR-11. 
10.- Guidelines for preventing opportunistic infections among hematopoietic stem cell transplant recipients. MMWR Morb Mortal Wkly Rep 2000 (October 20); 49 (R10): 1-128.

11.- Compendium of measures to prevent disease associated with animals in public settings, National Association of State Public Health Veterinarians, Inc. MMWR Morb Mortal Wkly Rep 2011; 60 (4):1-28.

12.- Abarca K, Dabanch J, Jofré L, Olivares R, Perret C, Rodríguez J, et al. Tenencia de mascotas en población sana e inmunodeprimida de Santiago. Anexo al Libro de Resúmenes del XIX Congreso Chileno de Infectología, Santiago, Noviembre 2002 (Late Breakers).

13.- Abarca K, López J, Peña A, López J C. Deficiencias en el cuidado y estado de salud de mascotas de niños inmunodeprimidos. Rev Chilena Infectol 2011; 28 (3): 205-10.

14.- Robinson R A, Pugh R N. Dogs, zoonoses and immunosuppression. J R Soc Promot Health. 2002; 122 (2): 95-8.

15.- Tassara R, Alarcón T, Larrañaga C, Wu E, Alvarez A M. Patología digestiva en niños infectados con el virus de inmunodeficienciahumana (VIH), en Santiago de Chile. Rev Med Chile 2003; 131: 19-24.

16.- Peña A, Larrañaga C, Wu E, Álvarez A M, Chávez A, Vizueta E, et al. Eventos oportunistas y enfermedad por citomegalovirus en niños chilenos infectados con VIH. Presentado en XIII Congreso Latinoamericano de Infectología Pediátrica y IV Congreso Ecuatoriano de Infectología, Agosto 2009, Guayaquil, Ecuador, modalidad poster.

17.- Neira P, Muñoz N, Wilson G, Barthel E, Rosales M y Henríquez C. Especies de Cryptosporidum en pacientes inmunodeficientes e inmunocompetentes de Valparaíso. Estudio descriptivo. Rev Chilena Infectol 2012; 29 (1): 63-71.

18.- López J, Abarca K, Paredes P, Inzunza E. Parásitos intestinales en caninos y felinos con cuadros digestivos en Santiago, Chile. Consideraciones en Salud Pública. Rev Med Chile 2006; 134: 193-200.

19.- Olivo I. Determinación de la presencia de Cryptosporidium sp en caninos domésticos mediante la tinción Ziehl Neelsen en la zona Sur de la Región Metropolitana. Tesis para optar al título de Médico Veterinario, Escuela de Medicina Veterinaria, Universidad Santo Tomás, 2006 no publicada

20.- Machuca J. Presencia de Giardia spp y Cryptosporidium sp en animales de tiendas de mascotas en la provincia de Santiago. Tesis para optar al título de Médico Veterinario, Universidad Santo Tomás, 2008.

21.- Alcaíno H, Gorman T, Alcaíno R. Flea species from dogs in three cities of Chile. Vet Parasitol 2002; 105 (3): 261-5.

22.- Parola P, Davoust B, Raoult D. Tick- and flea- born rickettsial emerging zoonoses.

Vet Res 2005; 36: 469-92.

23.- Labruna M, Ogrzewalska M, Moraes-Filho J, Lepe P, Gallegos J L, López J. Rickettsia felis in Chile. Emerg Infect Dis 2007; 13 (11): 1794-5.

24.- Pacheco R, López J, Lepe P, Abarca K, Ogrzewalska M, Richtzenhain L, et al. Detection of Rickettsia felis in Rhipicephalus sanguineus in Chile. Book of Proceedings, VI International Conference on Ticks and Tick-borne Pathogens (TTP-6), Buenos Aires, Argentina:2008 pág 274.

25.- González-Acuña D. Estado actual del conocimiento de las garrapatas (Acari: Ixodoidea) en Chile. Ciencia Ahora $\mathrm{N}^{\circ} 15$, año 8, Marzo-Abril 2005 http://www.cienciaahora.cl/Revista15/12GarrapatasEnChile.pdf (accedido 10 de enero de 2012).

26.- López J, Abarca K, Mundaca MI, Caballero C, Valiente-Echeverría F. Ehrlichia canis en un canino de la ciudad de Arica. Rev Chilena Infectol 2012; 29 (5): 535-8.

27.- Pérez M, Bodor M, Zhang C, Xiong Q, Rikihisa Y. Human infection with Ehrlichia canis accompanied by clinical signs in Venezuela. Ann N Y Acad Sci 2006; 1078: 110-7.

28.- López J, Abarca K, Cerda J, Valenzuela B, Lorca L, Olea A, et al. Surveillance system for infectious diseases of pets, Santiago, Chile. Emerg Infect Dis 2009; 15 (10): 1674-6.

29.- Roux V, Eykyn S, Wyllie S and Raoult D. Bartonella vinsonii subsp. berkhoffii as an agent of afebrile blood culture-negative endocarditis in a human. J Clin Microbiol 2000; 38(4): 1698700 .

30.- Mexas A, Hancock S and Breitschwerdt E. Bartonella henselae and Bartonella elizabethae as potential canine pathogens. J Clin Microbiol 2002; 40 (12): 4670-4.

31.- Duncan A, Maggi R, Breitschwerdt E. A combined approach for the enhanced detection and isolation of Bartonella species in dog blood samples: Pre-enrichment liquid culture followed by PCR and subculture onto agar plates. J Microbiol Methods 2007; 69: 273-81.

32.- Tsukahara M, Tsuneoka H, Lino H, Ohno K, Murano I. Bartonella henselae infection from a dog. Lancet 1998; 352: 1682.

33.- Ferrés M, Abarca K, Godoy P, García P, Palavecino E, Méndez G et al. Presencia de Bartonella henselae en gatos: cuantificación del reservorio natural y riesgo de exposición humana de esta zoonosis en Chile. Rev Méd Chile 2005; 133: 1465-71.

34.- Ferrés M, Abarca K, Prado P, Montecinos L, Navarrete M, Vial P. Prevalencia de anticuerpos contra Bartonella henselae en niños, en adolescentes y en una población de riesgo ocupacional en Chile. Rev Méd Chile 2006; 134: 863-7.

35.- García P, Poggi H, Lagos M, Romeo E,
Ferrés M, Zalaquet R, et al. Bartonella quintana: primer caso identificado en Chile. Libro de Resúmenes XXII Congreso Chileno de Infectología, Puerto Varas, Chile, 26-29 de octubre de 2005. Resumen p13, pág 50.

36.- Vásquez P, Chanqueo L, García P, Poggi H, Ferrés M, Bustos M et al. Angiomatosis bacilar por Bartonella quintana en un paciente con infección por virus de inmunodeficiencia humana. Rev Chilena Infectol 2007; 24 (2): 155-9.

37.- Larraín C, Paredes L, Rojas R. Enfermedad por arañazo de gato: linforreticulosis benigna de inoculación, una causa de adenitis subaguda a menudo inadvertida. Rev Méd Chile 1963; 91 : 286-9.

38.- Abarca K, Vial P, Rivera M, García C, Oddó D, Prado P et al. Infección por Bartonella henselae en pacientes inmunocompetentes: enfermedad por arañazo de gato. Rev Med Chile 1996; 124 : 1341-9.

39.- Wolff E, Muñoz M, Zapata C, Ledermann W. Enfermedad por arañazo de gato complicada con compromiso sistémico, osteomielitis osteovertebral y absceso paravertebral. Rev Chilena Infectol 2000; 17: 332-9.

40.- Rodríguez M, Giachetto G,Cuneo A, Gutiérrez M, Shimchack M, Pírez M. Enfermedad por arañazo de gato con compromiso óseo: Una forma atípica de presentación clínica. Rev Chilena Infectol 2009; 26 (4): 363-9.

41.- Navarrete M, Täger M, Wenzel M S, Podestá L, Pincheira M, Zaror L. Formas atípicas de enfermedad por arañazo de gato, Valdivia. Rev Chilena Infectol 2003; 20: 257-61.

42.- Peredo S, Viviani T, Peña A. Etiología del síndrome febril prolongado en niños. Rev Chil Ped 2007; 78 (5): 472-6.

43.- Lamas CC, Mares-Guia MA, Rozental T, Moreira N, Favacho AR, Barreira J, et al. Bartonella sp infection in HIV positive individuals, their pets and ectoparasites in Rio de Janeiro, Brazil: serological and molecular study. Acta Trop 2010; 115 (1-2): 137-41.

44.- Pons I, Sanfeliu I, Nogueras MM, Sala M, Cervantes M, Amengual MJ et al. Seroprevalence of Bartonella sp. infection in HIV patients in Catalonia, Spain. BMC Infect Dis 2008; 8:58.

45.- Obrist W. Seroprevalencia de Brucella canis en una población canina perteneciente a la comuna de San Bernardo, Región Metropolitana. Tesis para optar al título profesional de Médico Veterinario, Universidad Santo Tomás, 2005

46.- Sánchez, et al. Seroprevalencia de brucelosis canina por Brucella canis en clínicas veterinarias de la ciudad de Santiago. XX Congreso Panamericano de Ciencias Veterinarias, 2006, Santiago, Chile.

47.- Behravesh C, Ferraro A, Deasy M, Dato V, Moll M, Sandt C, et al. Human Salmonella 
infections linked to contaminated dry dog and cat food. Pediatrics 2010; 126: 477-83.

48.- Schotte U, Borchers D, Wulff C, Geue L. Salmonella montevideo outbreak in military kennel dogs caused by contaminated commercial feed, which was only recognized through monitoring. Vet Microbiol 2007; 119 (2-4): 316-23.

49.- Selmi M, Stefanelli S, Bilei S, Tolli R, Bertolotti L, Marconi P et al. Contaminated commercial dehydrated food as source of multiple Salmonella serotypes outbreak in a municipal kennel in Tuscany. Vet Ital 2011; 47(2): 175-90.

50.- J, Villouta G, Court A. Aplicación de una prueba inmunoenzimática en el diagnóstico de parvovirus canino tipo 2. Avances en Ciencias Veterinarias 1994; 9 (2): 134-7.

51.- Bond R. Superficial veterinary mycoses. Clin Dermatol 2010; 28: 226-36.

52.- García M y Blanco JL. Principales enfermedades fúngicas que afectan a los animales domésticos. Rev Iberoam Micol 2000; 17: S2-S7.

53.- Morris D, O’Shea K, Shofer F, Rankin S. Malassezia pachydermatis carriage in dog owners. Emerg Infect Dis 2005; 11 (1): 83-8.

54.- Anilio C. Identificación de agentes microbianos del conducto auditivo externo sano en caninos de raza Cócker spaniel. Estudio preliminar, 2008. Tesis para optar al título de Médico Veterinario, Universidad de las Américas.

55.- Gershman K, Sacks J and Wright J. Which dog bites? A case-control study of risks factors. Pediatrics 1994; 93(6): 913-7.

56.- Sacks J, Sinclair L, Gilchrist J, Golab G, Lockwood R. Breeds of dogs involved in fatal human attacks in the United States between 1979 and 1998. JAVMA 2000; 217(6): 836-40.

57.- Valdenegro F. Caracterización epidemiológica de las mordeduras ocasionadas por perros en un servicio de urgencia en la Región Metropolitana, Santiago de Chile. Tesis para optar al título profesional de Médico Veterinario. Universidad Santo Tomás, 2007.

58.- American Veterinary Medical Association Task Force on Canine Aggression and Human-Canine Interactions. A community approach to dog bite prevention. JAVMA 2001; 218 (1): 1732-49.

59.- Reisner I, Shofer F, Nance M. Behavioral assessment of child-directed canine aggression. Inj Prev 2007; 13: 348-51.

60.- Palacio J, León M, García-Belenguerb S. Aspectos epidemiológicos de las mordeduras caninas. Gac Sanit 2005; 19 (1): 50-8.

61.- Sacks J, Lockwood R, Hornreich J, Sattin R. Fatal dog attacks. Pediatrics 1996; 97: 891-5.
62.- Jofré L, Perret C, Abarca K, Solari V, Olivares R, López J. Recomendaciones para el manejo de mordeduras ocasionadas por animales. Rev Chilena Infectol 2006; 23 (1): 20-34.

63.- Harvey CE. Periodontal disease in dogs: Etiology, pathogenesis and prevalence. Vet Clin North Am Small Anim Pract 1998; 28: 1111-28.

64.- Woolfrey B, Moody J. Human infections associated with Bordetella bronchiseptica. Clin Microbiol Rev 1991; 4 (3): 243-55.

65.- Dworkin M, Sullivan P, Buskin S, Harrington R, Olliffe J, MacArthur R, et al. Bordetella bronchiseptica infection in human immunodeficiency virus-infected patients. Clin Infect Dis 1999; 28: 1095-9.

66.- Ner Z, Ross L, Horn M, Keens T, MacLaughlin E, Starnes V et al. Bordetella bronchiseptica infection in pediatric lung transplant recipients. Pediatr Transplant 2003; 7: 413-7.

67.- Quinn Py Markey B. Elementos de Microbiología Veterinaria. Sección II. Bacterias patógenas: Género Staphylococcus, $1^{\circ}$ Edición, Zaragoza, España, Editorial Acribia, 2005, pág 290.

68.- Rankin S, Roberts S, O’Shea K, Maloney D, Lorenzo M, Benson CE. Panton Valentine leukocidin (PVL) toxin positive MRSA strains isolated from companion animals. Vet Microbiol 2005; 108: 145-8.

69.- Sing A, Tuschak C. Hormansdorfer S. Methicillin-resistant Staphylococcus aureus in a family and its pet cat. N Engl J Med 2008; 358: 1200-1.

70.- Rutland B, Weese S, Bolin C, Au J, Malani A. Human-to-dog transmission of methicillinresistant Staphylococcus aureus. Emerg Infect Dis 2009; 15(8): 1328-30.

71.- Wulf M, Sorum M, Van Nes A, Skov R, Melchers W, Klaassen C et al. Prevalence of methicillin-resistant Staphylococcus aureus among veterinarians: an international study. CMI 2008; 14: 29-34.

72.- Jofré L, Cerva J L, López J, Díaz C, Noemí I, González C, et al. ¿Es posible la transmisión de huevos de Toxocara canis por contacto directo con cachorros? XLIV Congreso Chileno de Pediatría, Vol 75 (número especial) 2004. Libro de Resúmenes №22, pág 78, 2004.

73.- Estrada-Peña A, Venzal J M. Efficacy of several anti-tick treatments to prevent the transmission of rickettsia coronii under natural conditions. Ann N Y Acad Sci 2006; 1078 (1): 506-8.

74.- Braun S, Morales R, Méndez E, Orriols M, Ramos S, Triantafilo V. Infecciones por
Pasteurella sp: reporte de 20 casos en un período de quince años. Rev Chilena Infectol 2002; 19 (2): 74-8.

75.- Todd A. Florin, Beyond cat scratch disease: widening spectrum of Bartonella henselae infection. Pediatrics 2008; 121; e1413-25.

76. -English R. Cat-scratch disease. Pediatr Rev 2006; 27(4): 123-8.

77.- Breitschwerdt E, Kordick D. Bartonella infection in animals: carriership, reservoir potential, pathogenicity, and zoonotic potential for human infection. Clin Microbiol Rev 2000; 13 (3): 428-38.

78.- Buchmann A, Kershaw O, Kempf V, Gruber A. Does a feline leukemia virus infection pave the way for Bartonella henselae infection in cats? J Clin Microbiol 2010; 48 (29): 3295-300.

79.- Correa J, Segovia T, Rojas J. Detección de la infección por el virus leucemia felina mediante técnica de ELISA en Santiago, Chile. Arch Med Vet XXI 1989; 48-50.

80.- Cook A, Gilbert R, Buffolano W, Zufferey J, Petersen E, Jenum P, et al. Sources of Toxoplasma infection in pregnant women: European multicentre case-control study. Br Med J 2000; 321: 142-7.

81.- Montoya J, Liesenfeld O. Toxoplasmosis. Lancet 2004; 363: 1965-76.

82.- Jorge M C, Traversa M, Schettino D, Sanz H. Síndromes micobacterianos felinos y su importancia en la salud pública. REDVET rev. electrón vet. 2009; Vol 11 n 1 . http://www. veterinaria.org/revistas/redvet/n010110/011008. pdf, (accedido 12 de enero de 2012).

83.- Abalos P, Berríos P, Correa J, Luengo M. Aislamiento de parvovirus canino en perros con gastroenteritis. Arch Med Vet 1982; 14: 47-9.

84.- Toro C. Aislamiento del virus distemper de caninos sintomáticos. Tesis para optar al título de Médico Veterinario, Universidad Santo Tomás, 2010

85.- Gisel J, Brumble L, Johnson M. Bordetella bronchiseptica pneumonia in a kidney pancreas transplant patient after exposure to recently vaccinated dogs. Transpl Infect Dis 2010: 12: 73-6.

86.- Favi M, Bassaletti A, López J, Rodríguez L, Yung V. Descripción epidemiológica del reservorio de rabia en murciélagos de la Región Metropolitana. Chile. 2000-2009. Rev Chilena Infectol 2011; 28 (3): 223-8.

87.- Favi M,Yung V, Roos O, Rodríguez L, Trujillo R, Acevedo A. Evaluación de la capacidad inmunogénica de la vacuna antirrábica tipo Fuenzalida-Palacios (CRL) y de la vacuna antirrábica de cultivo celular (Verorab $\AA$ ) en personas con tratamiento preexposición. Rev Med Chile 2004; 132: 41-6. 